\title{
Challenges for transgene detection in landraces and wild relatives: learning from 15 years of debate over GM maize in Mexico
}

\author{
Sarah Z. Agapito-Tenfen ${ }^{1} \cdot$ Fern Wickson $^{1}$ (D)
}

Received: 17 November 2016/Revised: 7 November 2017/Accepted: 25 November $2017 /$

Published online: 2 December 2017

(C) The Author(s) 2017. This article is an open access publication

\begin{abstract}
Maize is one of the world's five staple cereals and its traditional varieties constitute a global resource critical to future agricultural development. Fifteen years ago, claims that transgenes had spread into traditional landrace maize in Mexico started an international discussion on the scale and significance of transgene flow from genetically modified (GM) crops to centres of crop origin and genetic diversity. The initial discovery of transgenes in landrace maize sparked an intense environmental dispute in which the culture and traditions of indigenous people were seen as threatened by the unchecked spread of biotechnological inventions from multinational corporations. This dispute was reflected in a political and legal battle over the regulatory status of GM crops in Mexico, which continues today as approvals of GM maize for cultivation remain subject to contestation in the courts. These legal, political and environmental disputes have been fanned by the existence of a significant scientific controversy over the methods for GM detection. The use of various approaches and a lack of harmonized methods specific for monitoring and detection of transgenes in landraces has generated both positive and negative results for GM contamination in Mexico over the years. In this paper, we review the peerreviewed literature on transgene detection in Mexican maize and highlight the challenges associated with transgene detection in landraces. In doing so, we identify the key methodological aspects under dispute and pinpoint the research bottlenecks and needs for building the capacity to effectively monitor transgene escape from GM crops to wild relatives or landraces.
\end{abstract}

Communicated by Daniel Sanchez Mata.

Fern Wickson

fern.wickson@genok.no

Sarah Z. Agapito-Tenfen

sarah.agapito@genok.no

1 GenØk Center for Biosafety, Siva Innovasjonssenter, Po Box 6418, 9294 Troms $\emptyset$, Norway 
Keywords GMO detection · Transgene flow · Genetic biodiversity · Agrobiodiversity · Maize

\section{Introduction}

Wild relatives are the ancestors of domesticated crop plants that continue to persist in the wild, while landrace varieties are those domesticated crops that have been traditionally bred and adapted over time to meet the needs of certain natural and cultural environments. Genetically modified (GM) crops can be spread into locations occupied by landraces and wild relatives via seed flow through formal and informal seed systems. Once there, transgenes can then be introduced into the genomes of landraces or wild relatives via pollen flow since pollen from GM crops has the potential to fertilize and further hybridize with female gametes in any sexually compatible species. The introgression of the transgene can then happen if repeated backcrosses occur and the transgene becomes stabilized in the new host genome (Stewart et al. 2003) (Fig. 1).

The potential for transgene flow into landraces and wild relatives is an important biosafety issue widely recognised around the world and therefore an important component of the regulatory risk assessments that are performed on GM crops prior to their approval for cultivation. A notable exception to this, which is of particular relevance to this paper, is the handling of GMOs in the United States of America (USA). In the USA, biosafety concerns relating to GM crops are often dismissed due to a belief that GM crops can be understood as 'substantially equivalent' to conventional crop plants and therefore not subject to any specific or rigorous risk assessment. The issue of transgene flow into landraces of traditional crop varieties has particular significance for countries that are centres of origin and diversity - such as Mexico is for maize. Transgene flow really hit the headlines as an important biosafety issue in scientific, public and policy circles when it was first reported as detected in Mexican maize in late 2001 (Quist and Chapela 2001).

In 2001 when transgene flow was first reported in Mexican maize, the import of GM maize for food and feed was permitted in Mexico and the vast majority of these imports came from the USA where GM maize was unregulated and unlabelled. The cultivation of GM maize was, however, not permitted in Mexico at this time. The Mexican government had implemented a moratorium on cultivation in 1998 due to concerns over potential impacts on traditional maize biodiversity. While the government granted approval for field
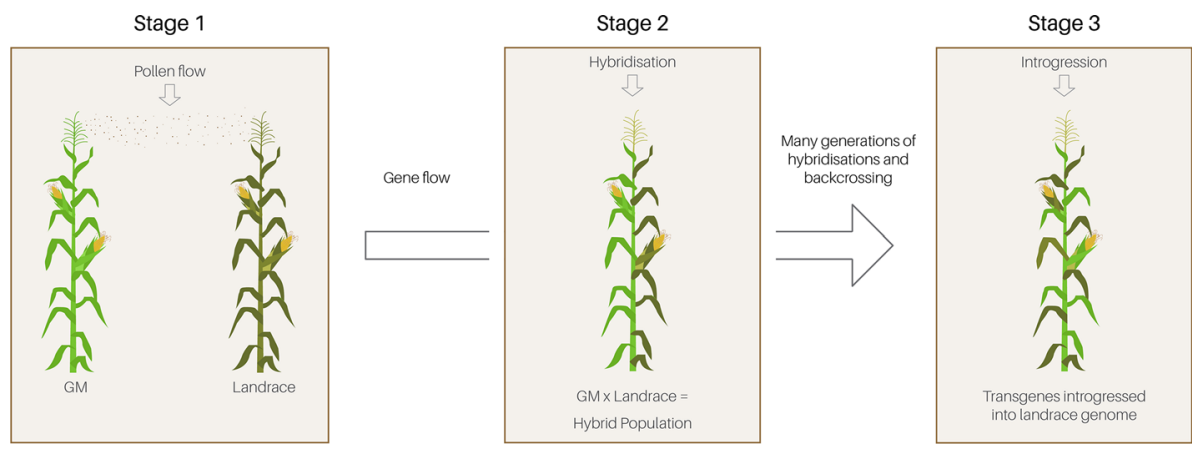

Fig. 1 Graphical representation of transgene flow by pollen in maize followed by hybridisation and subsequently to introgression events in landrace varieties 
trials of GM maize in 2009, in 2013 this became subject to a class-action lawsuit from a coalition of activist groups claiming that this threatened traditional biodiversity, with the judge in the case ruling that all planting be suspended until a final decision was made (Vargas-Parada 2014). Indeed, regulatory approvals for GM maize cultivation in Mexico are still (at the time of writing) subject to a high level legal dispute that continues to block their commercial use (Garcia 2017).

The case of transgene flow into landraces of maize in Mexico has now become an iconic debate. This is not only because maize is an important commodity crop and one of the five staple cereals that we currently depend on for global food security. It was also the first crop to be investigated for the presence of transgenes in its centre of origin and diversity. The reported spread of transgenes into Mexican maize then became a clear case of a highly technical debate extending beyond the scientific community to have significant relevance for and engagement from a range of other actors, including policy-makers, social scientists, civil society organisations, indigenous communities and farmer collectives. Indeed, a significant and active civil society movement against GM maize and in defence of native maize biodiversity has developed in Mexico after the initial reports of transgene detection (Baker 2013; Carro-Ripalda et al. 2015) and as stated above, court cases continue over the question of approvals for cultivation. This widespread interest in the issue is particularly due to the socio-economic and cultural importance of maize in Mexico (see Carro-Ripalda et al. 2015) (Fig. 2) and the socio-political nature of the controversy surrounding GMOs (Delborne 2008; Mercer and Wainwright 2008; McAfee 2008; Sarewitz 2004). Translating this interest in the issue to actually controlling transgene flow in Mexico is made particularly challenging by its geographic proximity to the USA and the high level of import that has been encouraged through the North Atlantic Free Trade Agreement (NAFTA) (Bello 2009). Furthermore, prioritising this issue for action is constrained by the availability of the

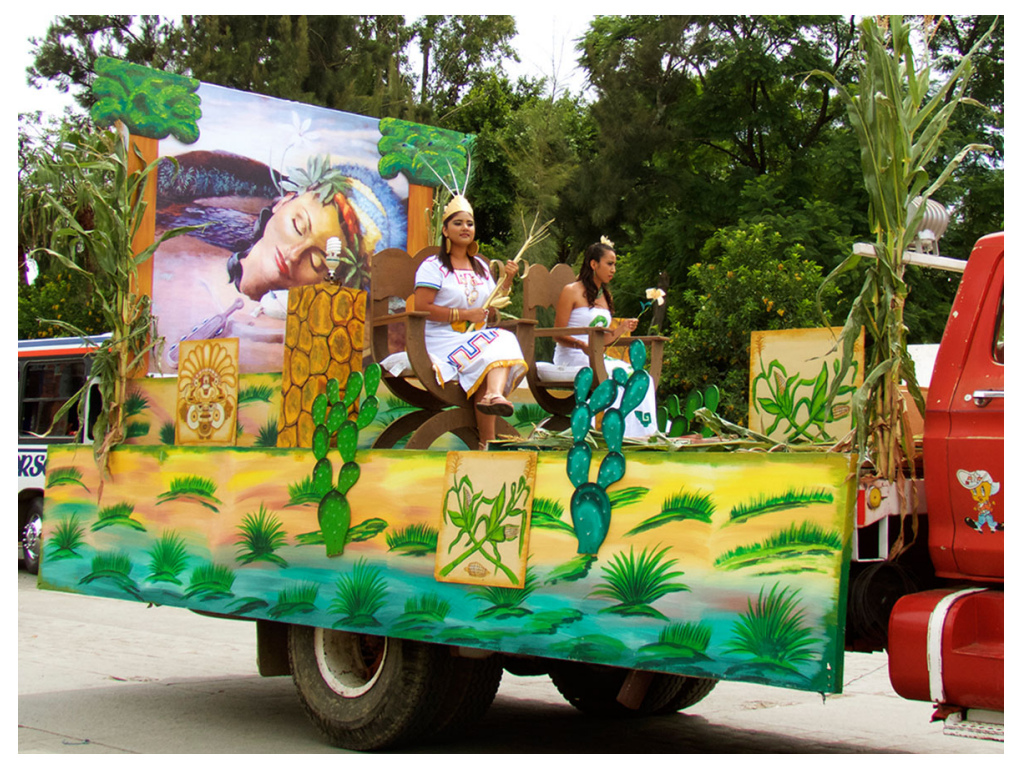

Fig. 2 Photo taken during La Guelaguetza festivities in Oaxaca State, Mexico. The photo shows Maize Goddess represented by a woman from the indigenous community. Photo taken by Sarah Agapito (20.07.2015) 
necessary economic resources and governmental will, and the issue's embeddedness in the broader context of threats facing landrace maize biodiversity, including climate change, low profitability, declining subsidies, and emigration away from rural communities (Wainwright and Mercer 2011; Mercer et al. 2012).

The first study to report the presence of transgenes in maize landraces in Mexico (Quist and Chapela 2001) was performed in a remote area of Oaxaca. It detected transgenic DNA sequences in landrace varieties using the methods of polymerase chain reaction (PCR) and nucleotide sequencing. These findings were published in the prestigious journal Nature but became hotly contested upon their release, with several critiques challenging the accuracy and legitimacy of the results subsequently being published (Metz and Fütterer et al. 2002; Kaplinsky et al. 2002; Christou 2002). These critiques pointed to a potential misinterpretation of the specific methodology used to claim that the transgene sequences were permanently incorporated (or 'introgressed') into the maize landrace genome. These critiques were then followed by a response from Quist and Chapela (2002), in which they provided additional data, using a different method, to support their original findings. This high level exchange sparked widespread scientific debate about the robustness of both the research methods and the results, ultimately leading to an unusual response from Nature in which they published an editorial note (appended to Quist and Chapela 2002) claiming there was insufficient evidence to justify the original publication, without going so far as to retract the paper.

After the initial study on transgene flow into landraces of maize became not only the subject of significant scientific debate but demonstrated its broader socio-political significance, others attempted to follow up and provide further evidence to address the contested question of whether transgene flow had taken place into landrace maize at its center of origin (Ortiz-García et al. 2005a; Serratos-Hernández et al. 2007; Piñero-Nelson et al. 2009a; Dyer et al. 2009). However, each follow up study that was performed to examine this issue used a different method and came to varying conclusions. The studies were also often subject to published critiques in which the methods used and interpretations applied were challenged (e.g. Cleveland et al. 2005; Schoel and Fagan 2009). Furthermore, there were also additional studies confirming presence conducted by both governmental authorities and non-governmental organisations that were never peer-reviewed and published, meaning the details of their methods remained obscure (Mercer and Wainwright 2008). The debate over transgene flow into landraces of maize in Mexico has therefore not only generated a broad socio-political debate on issues such as the industrialisation of agriculture, neoliberal trade policies, relations with the USA and threats to indigenous culture and livelihoods (Carro-Ripalda and Astier 2014), it has also been fraught with a scientific and technical dispute over what is the best/most appropriate and reliable method to use when seeking to detect transgenes in landraces and wild relatives and how to interpret the variance that can be seen in the results.

Transgene detection methodologies and techniques have certainly evolved since the controversial study in 2001, and although there is still no scientific agreement on the extent of transgene flow into landraces of Mexican maize (Gilbert 2013), it is now widely assumed that it is likely to be present, just at low levels that make detection particularly challenging. There is currently no internationally agreed and standardized approach to testing that is specific for the unique challenges associated with landraces and wild relatives and the low level presence that is likely. In this article, we therefore examine the methodological debate that has taken place over the last 15 years to extract lessons from this iconic case for future work on transgene detection in landraces and wild relatives. This review was motivated by a need to find an appropriate method for performing our own 
original empirical research on transgene presence in Mexican maize and finding the varying results and debates in the literature difficult to navigate. In this paper we therefore focus on presenting a comparative review of the experimental work that has been peerreviewed and published on this case to date and analyse the different methods used, especially in light of the published critiques directed towards them. Following this review, we discuss the major methodological issues and constraints that emerge and indicate how they still impede robust and reliable transgene detection in landraces and wild relatives. Highlighting what has been learned on this topic over the last 15 years of scientific work and methodological development, we then conclude by proposing what still needs to be done if we are to create robust and reliable test methods and monitoring for transgene flow into landraces and wild relatives.

\section{Results}

\section{Transgenes in Mexican maize}

In what follows, we review and describe the different methods used in all the peerreviewed experimental studies on transgene detection in landrace maize in Mexico. We also present critiques of the studies published in the academic literature, as well as any replies to these offered by the authors. We focus our attention in this review on the sampling strategies, analytical methods, and threshold levels applied to determine positive and negative results as these were the issues that were most often contested and in variance across the studies. This comparative information is then summarized in the format of an evidence table in Table 1 and analysed for lessons on what is important for future research involving transgene detection in land races and wild relatives.

\section{Quist and Chapela (2001, 2002)}

This study analyzed six Mexican landrace samples taken from four fields in two locations of Sierra Norte in Oaxaca, Southern Mexico. Out of these six samples, five presented positive results for transgene presence. Each individual sample consisted of a pool of grains from one cob, which due to the biology of maize involves a range of pollination events. In addition to this, a sample was taken from DICONSA, a governmental agency store that distributes subsidized grain for consumption. The research done on these samples can effectively be separated into two parts, the first investigating the presence of transgenes and the second the issue of introgression.

Within the first part of the work to detect transgene presence, end-point PCR targeting the 35-S promoter sequence (p35-S) from cauliflower mosaic virus (CaMV) (as well as an internal maize gene as a control), together with gel electrophoresis, were applied to amplify and visualize transgenic DNA. Although the authors make no reference to the threshold levels used for their detection, for the positive results they eye-visualized "weak" PCR amplifications in the gel, indicating a low-level presence of transgenes. In order to check these low PCR amplicons, the authors also performed a nested PCR, which consists of a second amplification reaction using internal primers for the obtained amplicons. The nested PCR method yielded significant amounts of amplification that were suitable for sequencing. The results of this sequencing revealed $98 \%$ homology to sequences used in biotechnological plant transformation. Thus the authors claim, confirming the transgenic 


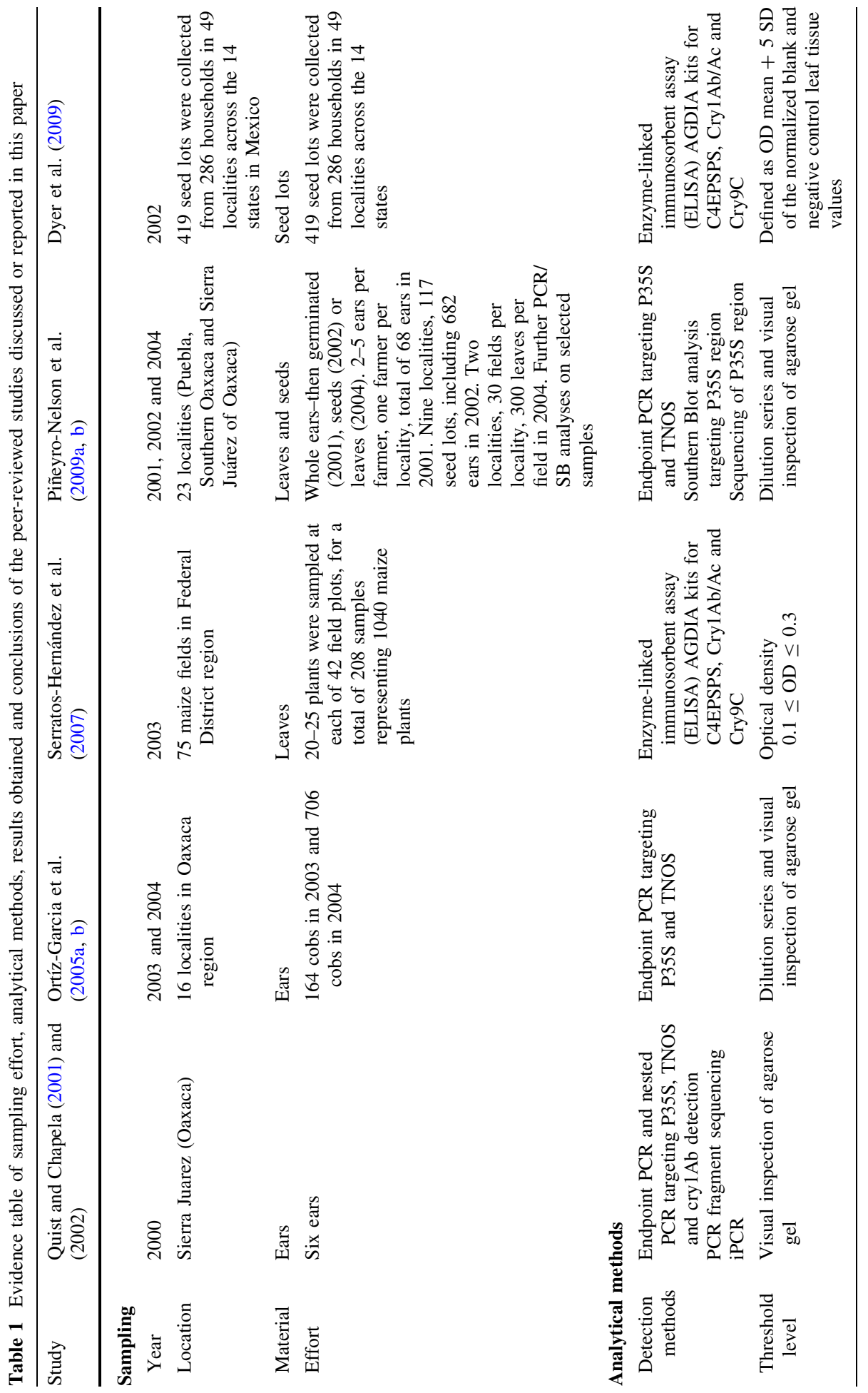




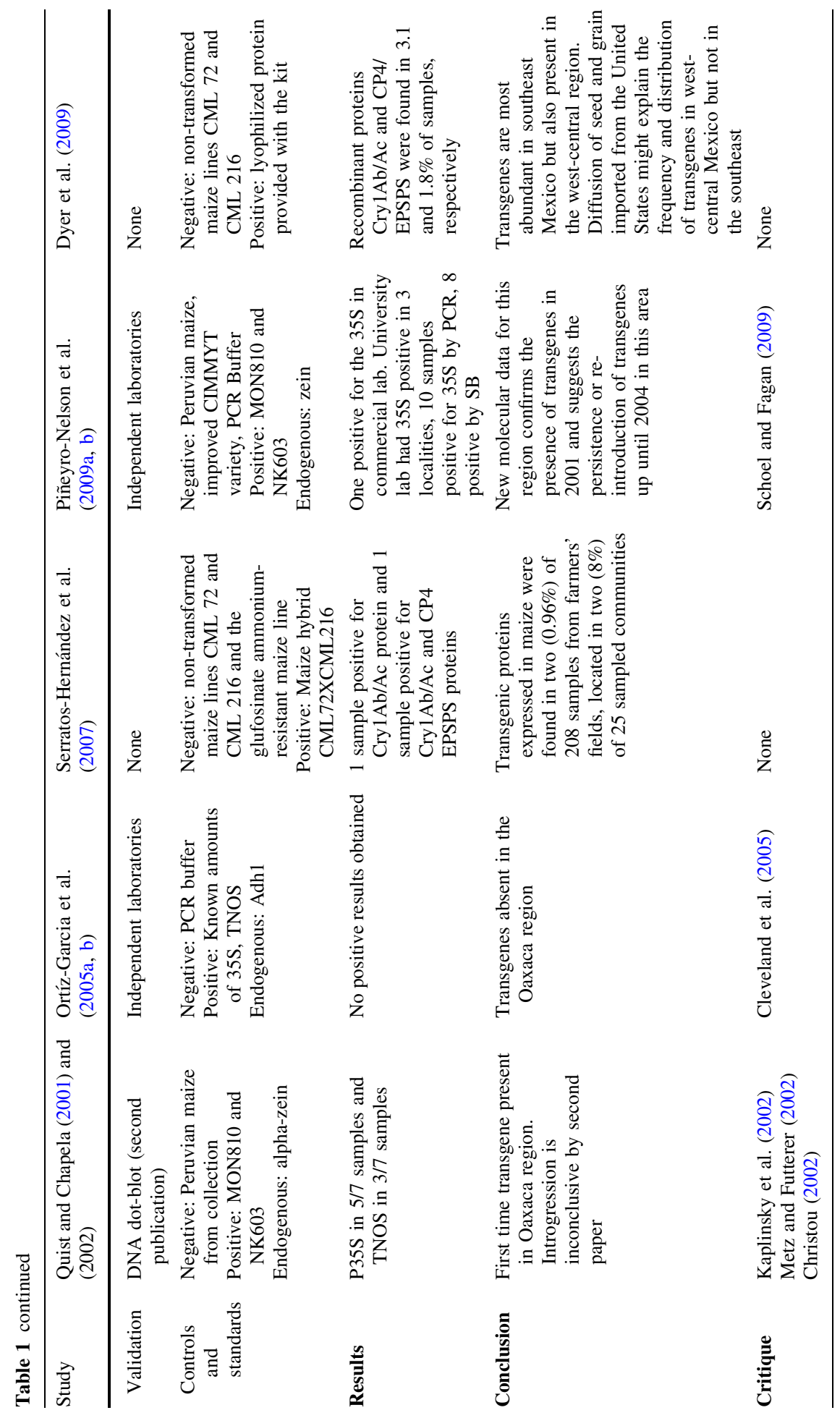


nature of the detected sequences. A third PCR targeting a different transgenic sequence (the nopaline synthase terminator sequence from Agrobacterium tumefasciens-T-NOS) also demonstrated positive results for two out of the six landrace samples, while a fourth PCR test targeting the Bacillus thuringiensis toxin gene crylAb was positive in one landrace sample.

In searching for p35-S and T-NOS, Quist and Chapela were applying a screening method based on primers that target common elements of many commercial transgenic constructs. This is still the most widely applied screening matrix worldwide (Bonfini et al. 2012; Block et al. 2013). The method of nested-PCR was used to confirm non-specific binding and the amplification of unexpected primer binding sites. Such nested-PCR methods are, however, no longer required to confirm target amplifications since real-time PCR has now been developed with the ability to apply fluorescent probes, which work as an internal primer and thus avoid unspecific amplifications (Wu et al. 2014).

The second aspect of the work in this first paper investigated the question of introgression by examining the genomic context in which the transgenic inserts were located. Here a method called inverse PCR (iPCR) was used to sequence DNA sequences flanking the detected p35-S amplicon. A range of different sequences was obtained and the authors suggested that this indicated that the transgene was inserted at multiple loci in the landrace host genome. The different flanking regions obtained were also interpreted by the authors as originating from multiple introgression events from a high frequency of gene flow between GM and landrace maize.

Inverse PCR is a strategy developed in the late eighties to provide information on one or both sides of a known DNA region (Triglia et al. 1988), or to clone coding or gene regulatory sequences from unsequenced species (Pavlopoulos 2011). The strategy is still used today but has also been frequently replaced by Southern Blotting or by highthroughput sequencing (Stefano et al. 2016). Although comparable results from all these techniques are obtained (Stefano et al. 2016), the main reason for iPCR disuse is related to the new techniques being faster and more easily adaptable to high throughput systems.

The two critiques of Quist and Chapela (2001) that were published in Nature in the following year (Metz and Fütterer et al. 2002; Kaplinsky et al. 2002) do not take issue with the first part of the study, but contest the question of introgression, i.e. the iPCR results. The critiques claim that the results were artifacts of the method and thus are inconclusive. In short, these authors argued that iPCR could generate unspecific amplicons from primer homology with other regions in the maize genome rather than just the transgenic flanking regions. Also, they stated that the amplicons obtained lacked transgenic sequences in either of the two ends and also restriction enzyme footprints that could confirm flanking sequences of the transgenic insert. These authors also criticized the study because no negative control was used to check these unspecific amplifications. Kaplinsky et al. (2002) proposed the use of Southern Blotting to provide reliable information about transgene introgression.

The conventional method for transgene copy number determination is Southern blot hybridization, which is surprisingly still used more than 40 years after its development. Southern blotting is a technique that enables the detection of a specific DNA sequence by hybridization with probes. However, Southern blot hybridization based transgene copy number determination is both costly, time consuming, and requires high quantities of highquality DNA. Real-time PCR has recently emerged as an alternative fast and affordable method. However, its accuracy and detection limit for transgene determination has been controversial (Yuan et al. 2007). Yuan et al. (2007) have reviewed studies of real-time PCR-based transgene copy determination and shown that very few publications have 
integrated proper statistical analysis and data quality control in real-time PCR based transgene copy number determination. In addition, as any nucleic acid technique that relies on base paring, $100 \%$ homology between target sequence and primer might not always be achieved. Nowadays, pairwise sequence alignments, such as those calculated by BLAST and FASTA, already include some potential mismatches in their calculation algorithms (Pearson 2014).

Quist and Chapela (2002) replied to these critiques of their work and acknowledged the misinterpretation of iPCR for some sequence results. Furthermore, to confirm their PCR results, the authors performed a second non-PCR method based on DNA-DNA hybridization (Dot-blot), which is similar to Southern blotting as suggested by Kaplinsky et al. (2002). The same samples were tested again and the results were confirmed. This provided further evidence for transgene presence in those samples but did not address the question of transgene introgression. By applying Dot-blot, Quist and Chapela were also not able to verify transgene copy-number or genomic location.

Beyond the exchanges in Nature, the editorial board of the journal Transgenic Research also published a methodological critique of the work (Christou 2002). As above, these authors challenged the iPCR results as technically flawed, thereby contesting the question of introgression. In addition to this though, they also proposed sample contamination during handling as the most likely explanation for the observed results (implying poor handling practices and highlighting the lack of methodological controls for this). They also argued that PCR was a method prone to artifacts and false indications and therefore suggested that the authors should have grown plants from their sampled grain and subjected those plants to more reliable forms of testing, suggesting also though that any transgene flow should have been phenotypically evident and "very obvious" in grown out samples. They also challenged the interpretation of the sequencing information and proposed that introgression would 'most likely' involve the whole transgenic cassette, with the type of recombination and rearrangement apparently observed by the authors being "highly improbable" in their view. Particularly, Christou and colleagues pointed to potential inconsistencies due to the fact that T-NOS sequences were not co-detected in p35-S positive results. It is now widely known that the most planted GM event at that timeMON810 - contains p35-S sequences but lacks T-NOS sequences due to transgenic rearrangements during the original transformation (Hernandez et al. 2003). Christou also suggested the use of Southern blotting to confirm transgene presence. While assumptions of what is likely and probable are arguably not robust reasons to doubt experimental results, it is worth noting that results that challenge expectations often face higher levels of scrutiny and critique and are held to a higher evidentiary standard than those confirming the status quo or existing beliefs.

\section{Ortiz-García et al. $(2005 a, b)$}

In the years following the initial study and the controversy that ensued, the Mexican government put some effort into sampling landrace maize for transgene detection (some of which was presented as a conference paper but never peer-reviewed and published). In the work that was published, the focus was placed on surveying the frequency of transgenes in landraces grown in the region where the presence had initially been reported (i.e. in the Sierra de Juarez area of the Sierra Norte region in Oaxaca). In this study (Ortiz-García et al. 2005a), fields in the region were visited twice, once in 2003 and again in 2004. 164 cobs were collected from a total of 16 localities in 2003 and 706 cobs from the same localities in 
2004. In 2004, a selection criterion for abnormal plants (smaller and less vigorous) was applied.

The method for detection that was used was end-point PCR (qualitative analysis) as used by Quist and Chapela (2001). The primers and the endogenous gene control also targeted the same elements as in Quist and Chapela (2002). The analyses were then carried out in three independent laboratories, two of which were commercial laboratories with claims of a quantification limit of $0.01 \%$ transgenic material, while the third lab was a governmental lab at the Instituto Nacional de Ecología in Mexico. Each laboratory analysed different grain subsamples and only one third of the collection from the 2004 sampling was analysed (by the laboratory at the Instituto Nacional de Ecología in Mexico). Dilution series were provided to establish the limit of detection by visual inspection of endpoint PCR and statistical tests were performed. This differed from Quist and Chapela who did not report any procedure for establishing a limit of detection. No positive results were obtained by end-point PCR in any of the laboratories. Based on their results and a statistical analysis of sample representativeness, the authors concluded that there was no evidence of transgene presence in Sierra Juarez in Oaxaca. This result added further fuel to the fire of the debate regarding the robustness of the results indicating transgene presence in landraces from 2001.

Although very little detail of the protocol is given in this paper, it seems that this survey used a very similar method for end-point PCR as that used by Quist and Chapela. However, Ortiz-García et al. (2005a) did not attempt to confirm or reproduce their results with a nonPCR method, like Southern blot, and interestingly, neither were they criticized for this. The most significant contribution of this study was its survey character, which accomplished sampling from many localities in the area. Strikingly though, neither this nor the Quist and Chapela work applied digital image analysis to the electrophoresis gels to allow for a more precise and reliable interpretation (Horgan and Glasbey 1995).

The only published critique that was directed at Ortiz-García et al. (2005a) proposed a different statistical method to estimate sample representativeness (i.e. how much of the area sampled would represent the Oaxaca region as a whole) and transgene frequency in a population (i.e. correcting for effective population size) (Cleveland et al. 2005). In this critique, the use of different statistical approaches was shown to lead to different interpretations and conclusions of the results, without altering the results per se. The critique essentially pointed to the limitations of the sampling effort when compared to the entire state of Oaxaca and thus claimed that the work could not be conclusive on the absence of transgenes in the whole state. Secondly, by applying the statistical correction proposed for the estimation of effective population size, the study of Ortiz-García et al. (2005a) was actually detecting transgenes at a $1-4 \%$ frequency instead of $0.01 \%$ as first stated. OrtizGarcía et al. (2005b) replied to this critique, rebutting the claims towards representativeness of the entire state of Oaxaca but accepting the effective population size correction. Both parties ultimately agreed that transgene frequencies between 1 and $4 \%$ or higher showed negative results in their study, while frequencies below that level might well be present but were not detected. In addition, they agreed that the sampling strategy covered only one area of the Oaxaca region and therefore could not offer representative results for the region as a whole.

\section{Serratos-Hernández et al. (2007)}

The investigation conducted by Serratos-Hernández et al. (2007) was the first to explore a region in Mexico other than Oaxaca and also to apply a non-DNA detection method. These 
authors investigated the presence of three specific transgenic proteins (CP4EPSPS conferring tolerance to glyphosate-based herbicides, Cry1 Ab and Cry9C conferring tolerance to insect species) by ELISA (Enzyme-Linked Immunosorbent Assay). They conducted these tests with maize leaf samples collected in 2003 in the Federal District. Their efforts revealed transgenic proteins expressed in two of 208 samples from farmers' fields $(0.96 \%)$, located in two of 25 sampled communities (8\%). Despite the novel confirmation of not just transgene presence but also protein expression in landraces in an area outside Oaxaca, the method and evidence provided in this paper received no published criticism by the scientific community.

ELISA is a protein-based method for GMO detection that is still widely used and is performed through extracting total crude proteins from a sample, adding water or a buffer, followed by sample homogenization. As for other protein-based detection methods, ELISA requires the use of antibodies to detect the transgenic protein and these are pre-coated on the inside of a micro-well plate. Following a series of steps, which allow the target protein to bind to the antibody, the bound protein is detected through a colour reaction that can be read by visual inspection (qualitative results) or by an optical plate reader (quantitative results). The advantages of ELISA in GMO detection are that it is more sensitive than other protein-based methods (e.g. lateral flow strips) and it does not require a lot of sample preparation as DNA-based methods do (CBD 2014). The main disadvantage is that proteinbased methods depend on the expression level of the targeted proteins, and these can vary depending on the plant tissue, the plant developmental stage and/or the transgenic event (Fraiture et al. 2015).

\section{Piñeyro-Nelson et al. $(2009 a, b)$}

Eight years after the initial detection of transgenes in landrace maize in Mexico, PiñeyroNelson et al. (2009a) revisited the Oaxaca region and brought three major elements to the debate: (1) a third analysis of sample collections from the same region and year of the previous study of Ortiz-García et al. (2005a), (2) an effort to reproduce results using two different techniques across four different laboratories and (3) a discussion of methodological considerations with suggestions for future follow-up studies. Importantly, this study followed up the debate in Oaxaca in which previous studies had shown both presence and absence of transgenes. The sampling effort for this study was much larger than the ones before it and included samples from 2001, 2002 and 2004 from 23 communities and more than 100 household fields, with some overlapping sampling to track transgene persistence over the years.

End-point PCR was applied to DNA samples extracted from germinated grains (2001), grain flour (2002) or leaves (2004) with primers targeting p35-S and T-NOS, as also applied in the previous two peer-reviewed studies focused on Oaxaca. The work provided evidence for the presence of $\mathrm{p} 35-\mathrm{S}$ in three localities from the 2001 collection, analysed by both end-point PCR and Southern blotting. Two independent labs in Mexico also analysed these samples and confirmed the results. Sequencing analysis was also performed with positive amplicons to confirm the nature of the p35-S sequence. Interestingly, Southern blotting could not confirm one positive result that was obtained by both labs and by PCR and sequencing, indicating the significance of using multiple methods but raising questions about how to interpret the results.

The 2002 collection was analysed by two laboratories - the commercial outfit of $\mathrm{Ge}$ netic ID, which was also the same commercial lab used in Ortiz-García et al. (2005a) and the public laboratory of Prof. Paul Gepts at UC Davis. The sub-sampling strategy was 
somewhat different for the two labs but both reported negative results by end-point PCR. The 2002 collection included nine localities but did not include the three positive localities from 2001. This collection was also the only one in which the plant material was grains and not leaves. The 2004 collection analysis confirmed two out of three positives for the localities from 2001 in the Instituto de Ecología laboratory at Universidad Nacional Autónoma de México. The third locality was not re-sampled.

In an attempt to control for potential false positives and negatives from the PCR method, 10 random positive and 10 random negative samples were sent to Genetic ID for validation and each of these were confirmed. From the positive samples, two were then selected for real-time PCR quantification and yielded 0.6 and $100 \%$ positive. Later, the occurrence of false negatives in the analysis of lyophilized leaf samples was also tested. In this case though, Genetic ID reported negative results for three leaf samples that the authors confirmed as positive for p35-S. The laboratory of Prof. Paul Gepts was able to support the authors' analyses, which included a blind sample with one transgenic seed in a sample of 1000 non-transgenic seeds and negative results from all of the 2002 seed samples ( $>17,000$ seeds) (Snow 2009).

The authors of this study note that although their results on seed-based detection provided no basis to suspect that false negatives occurred in either their own study or the analysis performed by Ortiz-García et al. (2005a), the unexpected variability in leaf-tissue results meant that PCR assays should be evaluated for the possibility of chemical and/or genetic compositions in landraces samples that might deviate from those used to establish detection limits (Piñeyro-Nelson et al. (2009a). Indeed, the verification of a method does not typically consider potential inhibitory components in the test sample that might affect PCR efficiency. This can, however, be done through conducting an inhibition test (Zel et al. 2012). While, inhibition tests can help identify if a sample contains PCR inhibitors and the potential of this to lead to false negative results, it will not actually solve the problem of having such inhibitory molecules in landrace samples.

Genetic ID researchers replied to Piñeyro-Nelson et al. (2009a) in a comment in Molecular Ecology (Schoel and Fagan 2009) and suggested that for a study of such importance, the investigation should have used real time qPCR analyses. Considering that the maize species (Zea mays) is diploid, the researchers argued that the only evidence of a positive result that would arise from DNA extracted from a single plant should contain one or two copies of the transgene per diploid genome. That means, either the same amount of DNA amplification as commercialized transgenic varieties (two copies of transgenes) or one copy of the transgene, in the case of a hemizygous plant. However, Piñeyro-Nelson et al. interpreted as positive levels that differed from $100 \%$ homozygote or $50 \%$ hemizygote samples. For the Genetic ID researchers, the low-level transgene presence (below $50 \%$ ) in a single plant analysis can only be explained by contamination in the laboratory since inhibition tests performed by their laboratory yielded no inhibitory effect in those samples. The interpretation by the Genetic ID researchers leads to the conclusion that Piñeyro-Nelson et al. (2009a) essentially came up with negative results in their survey of Oaxaca for transgenic maize, which would be consistent with the conclusions of OrtizGarcía et al. (2005a). They further highlighted that the sample size was too small in both studies (Ortiz-García et al. and Piñeyro-Nelson et al.), not representative of the Oaxacan maize population and thus, not sufficient to ascertain whether introgression of transgenic traits into the Mexican maize population had taken place or not (Schoel and Fagan 2009).

Piñeyro-Nelson et al. replied to the Genetic ID researchers and argued against the claims regarding lab contamination (Piñeyro-Nelson et al. 2009b). Piñeyro-Nelson et al. (2009b) provided statistical data to confirm that their positive results had a frequency 
pattern that could only arise in a probability of $<0.001$, which is highly unlikely. In addition, they stated that positive results were only accepted when sample results were consistent across different labs and techniques (PCR or Southern Blot). The authors also provided further data and evidence of variation in the internal gene control (zein gene) in hybrid varieties compared to landrace samples by applying a commercial kit of real-time quantitative PCR to detect p35-S (Taqman ${ }^{\circledR}$ GMO Maize 35S Detection Kit from Applied Biosystems). They also provided evidence from the literature of how diverse and heterogeneous genomes of maize landraces might interfere with PCR performance. In such cases, the positive profile of DNA extracted from a single landrace plant might not correspond to the same amount of transgenic amplification in modern hybrid plants. Furthermore, the reply also included an experiment in which positive samples were grown and their leaves sprayed with herbicide in order to test for transgene expression of the CP4EPSPS protein, which confers tolerance to herbicide spray. It also included experiments using ELISA for detection of Cry1 Ab/Ac protein, which confirmed the previously published results.

\section{Dyer et al. (2009)}

The publication of Dyer et al. (2009) appeared in the middle of the debate over the Piñeyro-Nelson et al. (2009a) publication. Sampling efforts in this study were larger (in terms of the area covered) than previous peer-reviewed publications and included several regions across Mexico, including 8 locations in 6 Mexican states. This study used a nonPCR method and investigated the presence of transgenic proteins (CP4EPSPS and Cry1 Ab/ Ac) by ELISA in seed lots sampled in 2003. The authors stated that in choosing this method they wanted to avoid technical problems associated with establishing the presence of recombinant DNA sequences from leaf tissue by PCR as happened in Piñeyro-Nelson et al. (2009b). Recombinant proteins Cry1 Ab/Ac and CP4EPSPS were found in 3.1 and $1.8 \%$ of samples, respectively. The proteins were most abundant in southeast Mexico (Veracruz State) but were also present in the west-central region (Guanajuato and Oaxaca State). A novel element of this study was the inclusion of a social dimension to the empirical data-estimating critical parameters of seed population dynamics using household survey data and combining these estimates with analytical results to examine presumed sources and mechanisms of dispersal. For the first time, their social data indicated that diffusion of seed and grain imported from the United States might explain the frequency and distribution of transgenes in west-central Mexico, although not in the southeast. This was the second time that transgenes were found to be present in areas outside the Oaxaca region, with a much larger sampling effort, and the evidence provided in this report also received no published criticism by the scientific community.

In summary then, the published empirical research on transgene flow into landrace maize in Mexico has involved: (a) studies conducted across different years, (b) studies conducted in different locations, (c) studies using a range of sampling strategies and sizes, (d) studies using different test materials (i.e. grains vs. leaves), (e) studies with different methods (end point PCR, real time PCR, ELISA, Southern Blotting, etc.) (f) studies with different limits of detection and $(\mathrm{g})$ studies providing different interpretations of the same data. It is perhaps therefore no surprise that results and conclusions have varied across them. What is particularly relevant to note though is that even within studies using the same material, different results have been obtained through the use of different methods, as well as across different laboratories performing the analysis (which may use slightly different procedures, subsamples or detection limits). Furthermore, although studies using 
the DNA-based technique of PCR have been critiqued in the published literature, interestingly both studies using non-DNA based methods to detect transgenic proteins have reported positive results without receiving methodological critique from the scientific community. This is despite the fact that ELISA, as any protein-based method, is also prone to false positives and negatives. False positives can for example occur when other proteins cross-talk with epitopes developed for target GM proteins (Prakoso et al. 2003). False negatives can occur if the concentration of GM proteins is below the limit of detection, which can happen because methods for GM protein detection depend on the expression level of targeted proteins and this varies according to the plant tissues and the plant developmental stage (Fraiture et al. 2015). Moreover, target proteins might be degraded or denatured by sample processing and any modification in the targeted proteins could alter the specificity and sensitivity of the assay (Fraiture et al. 2015). Also worth noting is that although studies have been done to show the potential for pollination and hybridization between transgenic maize and its wild relative teosinte (Baltazar et al. 2005) as well as experimental work to assess the relative fitness of such hybrids (Guadagnuolo et al. 2006), no empirical studies have yet been conducted and published on transgene flow into teosinte in the field.

Despite the controversy and high-level significance of this issue in scientific, policy and public arenas, no further experimental work on GM detection in landraces of maize in Mexico has been published since 2009. This lack of current research can arguably be linked to socio-political or economic factors such as a lack of governmental (or indeed international) will to actively support such research, a lack of finances available for complex and extensive testing, a prioritisation of other challenges facing maize biodiversity, and/or the difficulties related to the testing itself. Indeed, while the methodological limitations and ongoing uncertainty surrounding the most reliable and appropriate methods for transgene detection in landraces and wild relatives may not be the only reason for the absence of testing since 2009 , this methodological uncertainty clearly affects the ability to perform reliable research that can robustly stand up to critique and produce results that can be trusted to pass through peer-review to publication. In the following sections we therefore draw out exactly what these methodological challenges are and make recommendations for how to proceed with future research.

\section{Key methodological challenges}

The case of transgene detection in landrace maize in Mexico has been the subject of controversy and debate within political and scientific arenas for over 15 years now. As indicated in the review above and by others commenting on the case (Dalton 2009; Quist and Catacora-Vargas 2011; Gilbert 2013), different sampling and analytical methods have been used by research groups and commercial laboratories and have produced varying results and/or interpretations. The different results indicating both transgene absence and presence have significant implications for the political, legal and regulatory arenas (Bonneuil et al. 2014), as well as for the indigenous farming communities growing native maize (and from which the samples were typically collected). Although the debate is amplified by the social and political importance of the findings, there are legitimate differences in scientific method that allow the lack of consensus to persist. These different approaches in scientific method arguably remain debated because of the unique challenges facing transgene detection in landraces and wild relatives and the uncertainty that remains around how to handle detection of low level presence. 
Successful and sound detection of transgenes in landraces or wild relatives faces a number of unique methodological challenges that complicate the task of monitoring, particularly for the type of low level presence that is likely to occur in the field in places like Mexico where commercial cultivation is not approved. For example, transgenic DNA sequences or transgenic proteins must be intact and/or expressing to be detectable by current methods. Furthermore, methodological controls are typically based on endogenous genes or proteins and since these might differ in landraces and wild relatives, detection is dependent on developing relevant and adapted controls. However, all available detection methods also have intrinsic problems that become particularly relevant for working with landraces or wild relatives, such as quantitative limits for detecting small amounts of a substance. Only comprehensive and transparent detection methodologies can provide an estimation of the quantitative uncertainties involved (Box 1). In what follows below, we summarise what we see as the three key challenge areas of environmental sampling, DNA isolation in heterogeneous samples, and the potential for false positives and negatives in PCR.

\section{Environmental sampling}

Each of the peer-reviewed studies we examined used a different sampling strategy. Sampling strategies can vary depending on the biological question and hypothesis under investigation. Sampling to detect transgene flow into landraces and wild relatives has two major challenges. First, sampling the environment is often limited by available time and funds to perform the analysis and so difficult choices have to be made about the scope of sampling and how many samples to test. The main difference between environmental sampling and sampling food or a shipment of seeds or grain is that the boundary of the material to be tested is somewhat more clearly defined and limited in the latter cases. This helps in the estimation of presence percentage and transgene frequency. However, when it comes to landraces and wild relatives in the field, there is rarely an established boundary. Knowing the cultivation area (e.g. through empirical or geostatistical methods) can help to calculate the detection power of different sampling approaches. However, although a farmer's plot or a determined region/area may be considered a limit to determine a cultivation area of interest, it is important to remember that these almost never represent an actual barrier to transgene flow (Serratos-Hernández et al. 2004). Figure 3 shows the average size of a farmers plot in the Oaxaca region where most of the transgene detection studies were performed. It has been suggested that any sampling effort in landraces or wild relatives is therefore likely to underestimate the presence and/or frequency of transgenes in the sampled population (Quist 2007) and not detecting a transgene in a sample population therefore offers no guarantee that the population is in fact transgene free. The intrinsic uncertainty this creates means that the results are only really valid for that specific sample and it is difficult to calculate frequency for a wider area or community.

Sampling design also directly affects the statistical analysis (Dyer et al. 2009; van Heerwaarden et al. 2012). In our review, the majority of authors established the farmer's plot as the sampling unit, but each of the papers used a different sampling strategy and thus reached different conclusions about transgene frequency. As described in the review of the papers presented above, the statistical method used in Ortiz-García et al. (2005a) to estimate sample representativeness and transgene frequency in a population was challenged and the dispute over the most suitable statistical approach revealed problems with the paper's conclusions (Cleveland et al. 2005; Ortiz-García et al. 2005b). This was particularly in terms of what size sampling area would be sufficiently representative to allow 


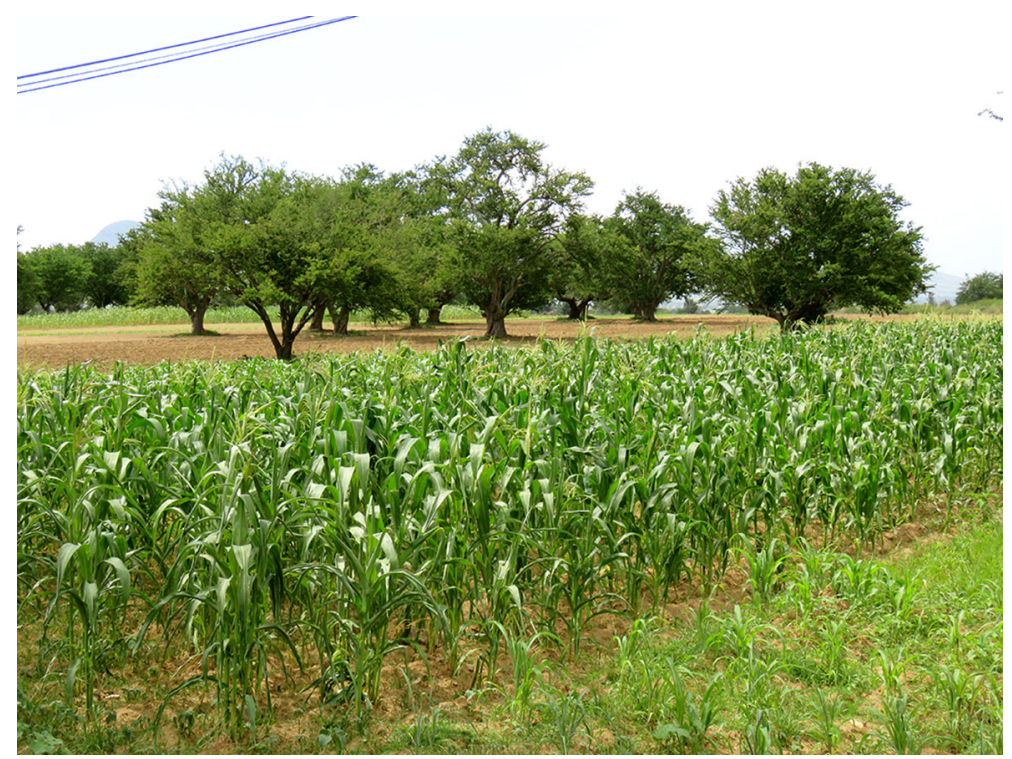

Fig. 3 Photo taken from farmer's maize fields in the Oaxaca region, Mexico. The photo shows different farmer's plot sizes, which can be distinguished by the different maize cultivation stages (vegetative stage VE, V3 and VT). Photo taken by Sarah Agapito (06.07.2015)

conclusions about the entire state of Oaxaca to be drawn and how the estimation of effective population size is performed to make claims regarding transgene frequency.

If the objective of sampling is to determine presence or absence of transgenes in an area, landrace populations should be identified with the highest probability of containing them (Cleveland et al. 2005). In those cases, reporting on the growing/environmental context and seed management practices is essential. On the other hand, if the objective is determining the frequency of transgenes in the landrace population of a given area, it is necessary to use a sampling strategy that maximizes the probability of finding rare alleles in the reference population and is also representative of that population (Cleveland et al. 2005). In this case, it is important to take them from the maximum number of sampling units at each level (e.g. numbers of seeds in ears, ears in fields, fields from as broad a range of environments within the reference area as possible). In addition, an equal number of seeds should be sampled from each sampling unit (Cleveland et al. 2005). These are concepts originating from population genetics and rarely applied to investigate transgene presence in centres of origin. Drawing on and making better use of state of the art knowledge in population genetics and dynamics could certainly help design the appropriate sampling strategy for specific transgene monitoring objectives and indicates the potential value of incorporating a range of different disciplines in the development of study method and design.

\section{DNA isolation in heterogeneous samples}

DNA-based detection methods such as PCR are undoubtedly the most commonly applied approach to transgene detection. Nonetheless, they depend on efficient DNA extraction, as well as strict cross-contamination controls. These are not pre-requisites specific to 
landraces and wild relatives but applying the standard quality control protocols might pose extra challenges to heterogeneous DNA samples, such as those from landraces.

Piñeyro-Nelson et al. (2009b) provided rich evidence of how heterogeneous genetic backgrounds might play a role in DNA extraction efficiency and, consequently, PCR quality. Piñeyro-Nelson et al. (2009a) suggested that the results obtained by Ortiz-García et al. (2005a) could have involved false negatives due to the expression of a variety of secondary metabolites in landrace samples inhibiting PCR amplification. This argument was not accepted by the commercial laboratory Genetic ID in their reply to Piñeyro-Nelson et al. (2009a), who confirmed that they had tested for PCR inhibitors through inhibition tests and did not find any such molecules (Schoel and Fagan 2009). Uncertainty does, however, remain regarding how much interference these characteristics might have on with PCR efficiency in detecting transgenes and internal control genes and how to adapt current methodologies to overcome these.

Routine DNA inhibition tests should be able to estimate any contaminants in extracted DNA (Zel et al. 2012). However, DNA extraction methods and DNA quality standards are frequently only tested in highly homogeneous samples, such as modern maize varieties. One example is the ISO method of nucleic acid extraction for the detection of genetically modified organisms and derived products (ISO 21571:2005). In applying such protocols, the DNA extraction from a landrace sample will most likely vary in both amount and quality due to its heterogeneity. The Guidance document from the European Network of GMO laboratories ENGL (ENGL 2011a) describes guidelines for how to introduce and verify a validated method in the laboratory. The document further acknowledges methodological bottlenecks, such as the impact of different instrumentation, PCR reaction mixes, primer concentrations, etc., but does not make any reference to heterogeneous samples or samples from landrace and wild relatives. For instance, the acceptance criteria for DNA concentration and quality is based on three conditions: the slope of the regression line must be between -3.6 and -3.1 ; the coefficient of determination $\left(\mathrm{R}^{2}\right)$ is equal to or above 0.98; and the difference between the measured $\mathrm{Ct}$ and the extrapolated $\mathrm{Ct}$ value $(\Delta \mathrm{Ct})$ is below 0.5 . In heterogeneous samples, these criteria might be very difficult to achieve because slight differences in DNA target and inhibitors concentrations might affect $\mathrm{Ct}$ values and therefore perhaps other criteria should be applied to measure extracted DNA quality from such sources.

\section{The potential for false negatives and false positives in PCR}

Although the ability to detect transgenic constructs is a pre-requisite for effective risk analysis, regulation and monitoring of GMOs (Lezaun 2006), this does not mean that the methods used necessarily operate in a flawless manner, nor that the knowledge available to carry out the methods is always complete. This is especially the case when the detection method is being applied to landraces and wild relatives rather the GM crop itself or its conventional alternatives. The ultimate transgenic DNA detection method of PCR is at the same time the most controversial. This is because PCR is an indirect method of DNA detection and relies on primer binding efficiency to target DNA sequences in the genome. Many inhibitory molecules can interfere with primer binding and DNA amplification, consequently leading to false negative results. On the other hand, primers are also prone to unspecific binding to highly homologous, but not identical, sequences, which might then lead to false positive results. False positive results might also arise from cross-contamination of samples during PCR reaction preparation. Therefore, many of the previous studies also performed other forms of confirmatory analysis, such as southern blots. 
Macarthur et al. (2007) have applied a model to examine the detection of unauthorized events in oilseed rape, Brassica napus, and in particular to explore how heterogeneity in the sampled lot affects the limit of detection (LOD), as well as how LOD values can be modified by choice of sampling plan, analytical replication scheme and reliable indication of false-positive rate. LOD refers to the lowest amount of transgenic material that the method is able to detect. The model of Macarthur et al. (2007) reveals three things: (a) that the LOD can vary by a factor of 100, depending on the degree of lot heterogeneity; (b) it can vary by an order of magnitude depending on the control plan used to detect GMOs, such as pooling of sub-samples and/or number of replicates; and (c) it can be underestimated by a factor of 20 if it is estimated using validation of the analytical method alone. The authors concluded that the three observations show the importance of an integrated assessment of the whole detection system and consideration of potential lot heterogeneity, which is frequently overlooked in practice (Macarthur et al. 2007). This is particularly the case for commercially prepared PCR kits for GMO detection, which still do not consider heterogeneous samples.

The LOD is always a critical matter. At near LOD concentrations, there is always a significant risk of false negative results for individual tests (Holst-Jensen et al. 2012). When transgene flow or introgression have taken place in a landrace or wild relative, the copy numbers of PCR targets (i.e. transgene elements) will most likely differ depending on both the number of transgene events that have occurred and the number of crossings. If two screening targets are present in a GMO but with different insert copy numbers, e.g. one and four, the relative LOD for these will differ four-fold for a DNA solution obtained solely from that GMO (Holst-Jensen et al. 2012). However, this information is always unknown. According to Holst-Jensen et al. (2012), the pragmatic approach is therefore to consider not only the observed presence/absence pattern but also the approximate absolute concentration of detected targets. While the latter can be extrapolated from standard curves, it should be remembered that there is a possibility that the target present in the GMO may exhibit slightly divergent PCR performance from the target present in the standards.

The practical evaluation of PCR parameters and acceptance criteria were established in 2008 by ENGL to validate qualitative and quantitative PCR methods, as well as in earlier efforts by others, such as FAO from 1998 and ISO from 2005 (Broeders et al. 2014). None of the published papers on GM detection in maize in Mexico make reference to the application of such international guidelines in their testing. Partly this is simply because these guidelines were not fully developed at the time of the first publications and for later studies, the authors may have found them fit for purpose. In fact, as noted in our review, PCR testing was frequently criticized and the call for non-PCR validation was observed in all critiques. International guidelines such as those from ENGL provide a set of parameters and acceptance criteria but do not mention the need for non-PCR methods to validate a PCR method, as was frequently called for in the Mexican case. 


\section{Box 1: measurement of quantitative uncertainty in transgene detection methods}

Every measurement is subject to some uncertainty and, therefore, a measurement result is only complete within scientific studies if a statement of its uncertainty accompanies it. Measurement uncertainties can come from different sources, such as: the measuring instrument, the item being measured, the environment, the operator, etc. These uncertainties can be estimated using statistical analysis of a set of measurements, or using other kinds of information about the measurement process (Bell 2001).

The most applied approach to calculate measurement uncertainty (MU) in the field of GMO detection is a top-down approach, in which data from collaborative trials (including all the factors influencing the MU during the analytical procedure) are used as a source for the estimation of MU. This approach is described in detail in the guidance document on measurement uncertainty for GMO testing laboratories produced by the ENGL working group on measurement uncertainty (Zel et al. 2012).

When the outcome of the measurement of uncertainty is not adequate (the performance characteristics do not satisfy all performance criteria set prior to the measurement), the method might be considered to be unreliable for its purpose.

\section{Discussion}

\section{Research needs and areas requiring attention for improving effective transgene detection in landraces and wild relatives}

Detecting the presence of transgenes depends on analytical methods and their measurement uncertainties and there is currently no agreed and defined framework or harmonized methods specific for the detection of transgenes in landrace varieties and wild relatives in which low level presence may be the norm (CBD 2014). There also seems to be a vacuum in the current international regulatory arena that deals with the potential risks of GMOs to the environment and animal and human health - the Cartagena Protocol on Biosafety under the umbrella of the Convention on Biological Diversity-since it also gives no specific attention to the unique challenges facing GM detection in landraces and wild relatives.

Despite the lack of clear international guidelines specific for sampling and testing heterogeneous and dispersed landraces and wild relatives, and the pitfalls and potential misapplications highlighted above, transgene detection methods have developed significantly over the last 15 years. There is now an immensely valuable set of tools, approaches and international guidelines that continue to develop and provide a way to evaluate transgene presence. To support this ongoing development and to steer it in directions that are particularly useful for addressing the challenges associated with detection in landraces and wild relatives, here we offer lessons from our review of the published literature and scientific debate on the Mexican maize case for future work in this area.

The determination of a positive or negative result from a transgene testing analysis has two major stages. The first stage is related to the analysis and control of steps prior to the endpoint measurement (e.g. sampling strategy, DNA extraction, PCR reaction, crosscontamination, etc.) that might affect the value obtained in the endpoint measurement. In other words, what are the factors affecting the $\mathrm{Ct}$ value obtained in real-time experiments or the presence, absence or even the intensity of a band in a gel, and the confidence in the 
obtained value? The second stage is then the interpretation of the endpoint measurement. We discuss issues connected to both of these stages in turn below.

The start of any study is clearly sampling and for the challenges associated with environmental sampling, it is important to have established a priori what scope of inference the research is going to take and then use this to help identify the appropriate sampling strategy. For environmental sampling and GMO monitoring in landraces or wild relatives, particular attention should also be given to identifying the environmental protection goals that are of interest, including what is important for different stakeholders such as regulators, farmers, researchers etc. (Wickson et al. 2013; Wickson 2014). This can help to guide the selection of boundaries for the environmental sampling. A classification of ecoregions for environmental and GMO monitoring networks has been proposed by Graef et al. (2005). These authors suggest that a variety of ecological data should be combined with socio-economic data (such as land use), to help integrate spatial and temporal complexity and heterogeneity of ecosystems being surveyed and thus provide more reliable, accurate and reproducible data. Rather than random sampling, in such an approach, sampling is a stratified procedure integrating different layers of information. The authors also highlight that GMO monitoring networks must be integrated with agricultural data and might also require adaptation and improvement with regards to its implementation over long periods of time and large areas, such as in many agriculture-based regions or countries (Graef et al. 2005).

An important element of environmental monitoring is also the temporal factor. The previous studies on transgene detection in Mexican maize landrace, particularly the Piñeyro-Nelson et al. study (2009a) showed temporal-dependence of transgene frequency. Especially for land use data, in which the agricultural landscape might change more frequently even within a single year depending on the crop season, integration of a temporal dimension to environmental sampling strategies and design can be learned from landscape structure analysis (Waltz et al. 2016).

Environmental sampling strategies need to try and reflect the geographic heterogeneity of occurrence and agricultural use of the species in question in order to estimate percentage and frequency of transgene presence. This is of course highly challenging in the context of maize in Mexico and indeed handling this heterogeneity is arguably the primary challenge facing a determination of transgene frequency using environmental sampling. Transgene frequency must be determined based on the population size that has been sampled. Sampled material, e.g. seeds, cobs or leaves, directly affects statistical calculation of transgene frequency and therefore, inference of transgene presence in a region/sample. Cleveland et al. (2005) describes the maternal effect (when seeds are taken from few cobs versus seeds taken from a seed lot or a mixture of many harvested cobs) on transgene frequency estimation. This is because seeds from the same cob are over representing maternal genetic contribution but also because in maize each seed contains layers of tissues (e.g. endorsperm, seedcoat, embryo) (Fig. 4) with different genomic material. Therefore, since maize genetic structure directly influences DNA-based (e.g. PCR) detection and quantitation; DNA extraction from single plants can provide different results from DNA extractions using a pool of plants (or seeds). As a consequence, it can influence the establishment of a link between the way GM concentrations are determined in seed, feed, food and in the environment (Holst-Jensen et al. 2006). Several guidelines are provided in Trifa and Zhang (2004), Cleveland et al. (2005), and also in Holst-Jensen et al. (2006) for calculating effective population size and transgene frequency depending on sample material and size. It is important to realise that each of these proposed guidelines will need to be considered and tailored to the specific material and sample size in use and that it may not be possible to harmonise a single ideal across them. 


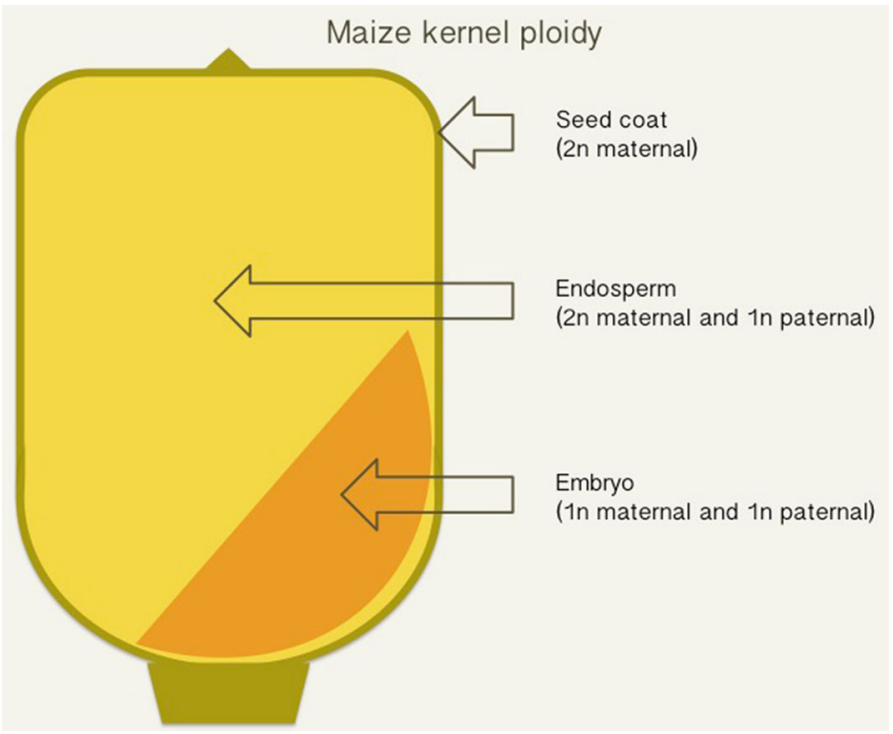

Fig. 4 Simplified graphical representation of a maize kernel shows the endosperm and embryo, both of which are products of the double fertilization of sperm cells (paternal) and polar nuclei and egg cell (maternal), respectively. The entire kernel is covered with a diploid maternal tissue called seed coat or pericarp

For the challenges associated with DNA extraction and PCR inhibition, the key issue is to ensure high quality DNA. Throughout the years, different methods for GMO detection have been validated using certified reference materials that are in the form of powdered grain material. However, every-day routine laboratories must perform GM detection on a wide variety of sample matrixes. In such cases, molecules of plant origin or from other sources that affect PCR amplification will influence the reliability of transgene detection. The extraction method is therefore key to ensure high yield and quality of the DNA obtained and must be carefully selected or adapted.

Cankar et al. (2006) have analysed the effects of DNA extraction methods and sample matrices on quantification of GMOs. These authors tested four maize and four soybean samples and found crucial influences on the results of GMO quantification from the extraction technique and sample matrix properties. Although they suggested the development of appropriate extraction techniques for each matrix, the authors also highlighted that for samples with certain compositional specificities, it will be impossible to define strict quality controls, such as acceptance criteria to compare the efficiency of the sample to that of the standard curve, to be introduced to monitor PCR (Cankar et al. 2006). Adaptation of DNA extraction protocols for heterogeneous samples will then have to be done by different groups and is most likely unable to be harmonized for all GMO detection work. In addition, new quality control measurements might have to be developed since current amplification of an endogenous positive control gene, as an indicator for the absence of PCR inhibitors, is not always valid (Holden et al. 2003).

Much can be learned from other sciences that deal with genetic analysis of non-model species as well as from food science, which frequently works with highly processed and altered materials. Schrader et al. (2012) reviewed the literature providing general 
guidelines for PCR inhibitors removal that could also be applied to heterogeneous samples being tested for GMO content. In fact, while it arguably always goes back to the assessment of PCR inhibitors by PCR control reactions, for most of the inhibitory substances, practicable tools for their analysis are yet to be developed and therefore this could be an important area for future research in this field (Schrader et al. 2012).

Turning to the second stage of GM detection work, the interpretation of endpoint measurements, it is relevant to note that an endpoint measurement can be interpreted as a positive or negative result depending on the threshold level established for the analysis. Generally, most GMO detection and identification methods have been developed to meet the purpose of fitting into a labelling requirement/law. This means that the threshold levels are set to the labelling requirement (e.g. $0.9 \%$ presence of a GMO in a food sample) and the tested sample is determined positive if equal or above that limit or negative if below that limit. Holst-Jensen et al. (2006) have discussed coherence between legal requirements and analytical approaches for detection of GMOs and have recommended key points where coherence should be developed. These include: (a) the definition of units of measurements, (b) expression of GM material quantities, (c) terminology, and (d) inconsistent legal status of products derived from related but slightly different transformation routes. Although some improvement has been achieved in this area, such as the decision by the European Commission to recommend the use of DNA ratios to express GMO quantity (Commission Regulation (EU) No 619/2011), the debate still continues to focus on GM labelling laws and does not necessarily include GM detection for environmental monitoring. Thus, such analytical coherence is not necessarily fit for the purpose of analysing GM contend in landraces and wild relatives.

Given that Europe has established strict requirements for GM regulation, detection and labelling, significant development in setting guidelines for testing and endpoint measurements has been achieved by the European Network of GMO Laboratories, hosted by the Joint Research Centre of the European Commission (http://gmo-crl.jrc.ec.europa.eu/). However, this work is generally developed for application within the European context and therefore does not include guidelines for GM detection in landraces and wild relatives, nor does it take account of the socio-political realities of other regions or countries in which this issue may be of lower cultural or economic priority. Whereas low-level presence (e.g. $\mathrm{Ct}$ values close to final PCR cycles) might not generate labelling concerns, it might well be relevant for environmental risk assessment. The Guidance document from ENGL "Overview on the detection, interpretation and reporting on the presence of unauthorised genetically modified materials" recognizes the absence of a solid reference framework, the interpretation and reporting of results on unauthorized GM presence and recommends primarily focus on reliability. The document further provides a brief general consideration on convergence between datasets and ruling out or minimising the possible occurrence of false positives or negatives (ENGL 2011b). Therefore we propose that it is crucial that future work in this would benefit from the development of guidelines beyond a European context on how to proceed to verify and confirm positive results for the types of low level presence that are likely to be typical in the case of contamination of land races and wild relatives in centres of origin and diversity.

Finally, given the debate and learning that has occurred in the Mexican maize case, we propose that future research on transgene detection in landraces and wild relatives should also work to include the collection of socio-cultural data to help develop a comprehensive view of gene flow and its influence on both maize and human populations. This collection of socio-cultural data in addition to samples for genetic testing can include information such as how seeds are acquired and selected. Questions of relevance here are whether seed is saved or purchased, the extent to which grain sold for consumption may also be planted, 
whether seeds are exchanged within the community and/or with other communities, whether migrating community members ever bring return with new seeds, what characteristics are favoured in processes of seed selection, whether planting time varies across plots or varieties etc. This type of information can usefully help to build a complementary understanding of local seed systems and management practices in the areas being sampled. It can also help build an understanding of how the work and choices of farmers can affect landrace population structure and dynamics, as well as how such practices may work to contain or spread transgene contamination.

It is clear that significant work remains to be done to optimize and potentially standardize GM detection methods for working with landraces and wild relatives in which it is likely that any presence of transgenes will be at low levels. It is also clear that although the field has evolved significantly and useful new techniques have been developed to detect even smaller traces of transgenes in a sample, the cost of applying such methods across a broad enough sample to be representative is still a major inhibiting factor. It is certainly questionable to what extent the farmers growing landraces of maize are able to afford to carry on such analyses, and to what extent the governments of centres of crop origin and diversity are willing and able to pay for testing of either landraces or wild relatives. The situation becomes even more challenging and urgent as we realize that these problems exist and persist for the GMOs that are commercially available today while new GMO events continue to be approved all the time.

Although the number of GM events has increased from less than 10 events in 1998 to over 500 today (https://bch.cbd.int/database/lmo-registry/), only basic information on each event is available and this does not include the level of sequence information that is needed to develop detection methods (due to claims to confidential business information) (Nielsen 2013). It is also relevant to note that only Parties to the Cartagena Protocol have a legal duty to release information about new GMO approvals and the largest GMO adopter - the USA — is not a Party to the Protocol. To advance the ability to effectively monitor for GM spread, regulatory agencies need to make publicly available information on all GM events they approve and developers need to make information on transgene sequences and reference materials available.

Furthermore, it is important to note that while the first wave of GMOs were relatively similar (e.g. all using the same promoter P35s, which allowed for a broad based screening in a nonevent specific manner), the field is evolving quickly and new GMOs share little similarity, making it harder to detect a wide range of events by using a screening matrix. The field of biotechnology also now uses techniques beyond recombinant DNA technology and not all GMOs are made to contain a transgene (e.g. gene-edited crops) or to produce a transgenic protein (e.g. dsRNA-based GMOs) (Heinemann et al. 2013). Crops resulting from these techniques can be difficult to distinguish from conventionally bred crops or from crops produced by natural genetic variation, and their identification therefore poses a whole new level of complexity for the field in the future. With these new developments of GMOs, sampling, detection and identification becomes only more challenging and complex. It is therefore urgent that work to develop robust and reliable methods for the detection of transgenes in landraces and wild relatives advances at a similar pace as the development of GM technologies.

\section{Conclusion}

The importance of conserving genetic biodiversity in important agricultural crop plants and the rapid expansion of biotechnological techniques and GM organisms makes establishing good practices for transgene detection in landraces and wild relatives only more urgent and 
pressing now than it was 15 years ago. In this article, we have reviewed all of the published studies examining the extent to which transgene flow has occurred into landraces of maize in its centre of origin and diversity Mexico. Each of these studies used different methods, came to varying conclusions and has been subject to divergent interpretations of the results and their meaning. The key issues of debate have included appropriate methods for environmental sampling and the scale of inference possible on the basis of this, the ability to isolate high quality DNA from heterogeneous samples using established methods, and the potential for PCR methods to lead to both false negative and false positive results.

The scientific debate over what constitutes a reliable and effective method for DNA detection in landraces and wild relatives with low level presence, as well as how to interpret variation in results generated using different methods, only serves to perpetuate public and policy uncertainty and debate in an area that is already highly controversial. As biotechnologies continue to evolve and expand, it is becoming increasingly urgent that methods for detecting transgenes in landraces and wild relatives, and particularly low levels of presence, are further discussed, developed and supported so as to better address the unique challenges involved. It is crucial that the limitations of existing approaches are transparently acknowledged and recognized, both within the scientific community but also within national and international policy contexts.

\section{Box 2: Recommendations for future research directions}

\section{Sampling}

* Integrate social and ecological data to help determine environmental protection goals and guide environmental sampling

* Consider the temporal dimension affecting transgene frequency and design sampling (and/or interpret results) accordingly

* Decide how to best handle geographic heterogeneity if there is an aim to calculate percentage or frequency of transgenes

\section{Testing}

* Establish threshold levels and limits of detection that are relevant for environmental monitoring of low level presence

* Adapt the DNA extraction protocols to be as efficient as possible for the particular heterogeneous sample in use

* Test for potential PCR inhibitors and work to develop additional quality control measures when an endogenous positive control gene is not valid

* Use multiple methods and inter-laboratory testing to validate the methods and results

\section{Policy}

* Ensure that there is open access to transgene sequence information and that all event approvals appear in a public registry

* Establish monitoring networks that can be linked to existing agricultural data and databases

* Develop international guidelines for verifying and confirming low level presence in reference materials

* Have clear information requirements for publications reporting on transgene detection in wild relatives and landraces to enhance reliability and consistency 
Learning from 15 years of scientific research and debate on the iconic case of transgene flow into landraces of maize in Mexico has revealed that future work in this field will benefit from (summarised in Box 2): more considered approaches to environmental sampling (which are followed up with ongoing monitoring over time), better guidance on establishing limits of detection and enhancing the ability to detect low level traces of transgenes, improved validation of the results (e.g. using both inter-laboratory validation and multiple methods), the setting of a minimum level of information for publication of transgene detection analysis in wild relatives and landraces (with guidelines targeting the reliability of results to help ensure the integrity of the scientific literature), a promotion of the importance of developing consistency between studies, an increase in transparency and reporting on experimental methods and reasons why choices for one or another were made, and increased support and resources dedicated to the ongoing development and application of detection strategies. Without such improvements in this field, the future of GM detection in landraces and wild relatives is almost certainly going to be one of continued controversy, uncertainty and debate.

Acknowledgements We would like to acknowledge the support of the indigenous communities of Oaxaca that have been participating in our project for sharing their knowledge, seeds and insights into context of maize farming in Mexico. We would also like to thank Dr. Gretta Abou-Sleymane, Dr. Miluse Trtikova and $\mathrm{PhD}$ student Narmeen Mallah for insightful discussions about transgene detection methodologies during a project workshop. This work was supported by the Research Council of Norway under the LATINAMERIKA Program [Grant Number 236840].

\section{Compliance with ethical standards}

Conflict of interest The authors declare that they have no conflict of interest.

Open Access This article is distributed under the terms of the Creative Commons Attribution 4.0 International License (http://creativecommons.org/licenses/by/4.0/), which permits unrestricted use, distribution, and reproduction in any medium, provided you give appropriate credit to the original author(s) and the source, provide a link to the Creative Commons license, and indicate if changes were made.

\section{References}

Baker LE (2013) Corn meets maize: food movements and markets in Mexico. Rowman and Littlefield Publishers, Lanham

Baltazar BM, de Jesús Sánchez-Gonzalez J, de la Cruz-Larios L, Schoper JB (2005) Pollination between maize and teosinte: an important determinant of gene flow in Mexico. Theor Appl Genet 110(3):519-526. https://doi.org/10.1007/s00122-004-1859-6

Bell S (2001). A Beginner's guide to uncertainty of measurement. In: measurement good practice guide no. 11 (issue 2). Teddington, Middlesex, UK

Bello W (2009) Food wars. Verso, New York

Block A, Debode F, Grohmann L, Hulin J, Taverniers I, Kluga L et al (2013) The GMOseek matrix: a decision support tool for optimizing the detection of genetically modified plants. BMC Bioinform 14:256. https://doi.org/10.1186/1471-2105-14-256

Bonfini L, van den Bulcke MH, Mazzara M, Ben E, Patak A (2012) GMOMETHODS: The European Union Database of reference methods for GMO analysis. J AOAC Int 95(6):1713-1719

Bonneuil C, Foyer J, Wynne B (2014) Genetic fallout in biocultural landscapes: molecular imperialism and the cultural politics of (not) seeing transgenes in Mexico. Soc Stud Sci 44(6):901-929

Broeders S, Huberb I, Grohmannc L, Berbend G, Tavernierse I, Mazzaraf M et al (2014) Guidelines for validation of qualitative real-time PCR methods. Trends Food Sci Technol 37(2):115-126. https://doi. org/10.1016/j.tifs.2014.03.008

Cankar K, Stebih D, Dreo T, Zel J, Gruden K (2006) Critical points of DNA quantification by real-time PCR-effects of DNA extraction method and sample matrix on quantification of genetically modified organisms. BMC Biotechnol 6:37. https://doi.org/10.1186/1472-6750-6-37 
Carro-Ripalda S, Astier M (2014) Silenced voices, vital argument: smallholder farmers in the Mexican GM maize controversy. Agric Hum Values 31:655-663

Carro-Ripalda S, Astier M, Artia P (2015) An analysis of the GM crop debate in Mexico. In: Macnaghten P, Carro-Ripalda S (eds) Governing agricultural sustainability: global lessons from GM crops. Routledge, London, pp 33-73

CBD - Convention on Biological Divesity (2014) Summary of the activities under the electronic network of laboratories for the detection and identification of living modified organisms (2012-2014). http://www. cbd.int/doc/meetings/bs/mop-07/information/mop-07-inf-09-en.pdf, United Nations Environment Programme Convention for Biodiversity; http://www.cbd.int/doc/meetings/bs/mop-07/information/ mop-07-inf-09-en.pdf

Christou P (2002) No credible scientific evidence is presented to support claims that transgenic DNA was introgressed into traditional maize landraces in Oaxaca, Mexico. Transgenic Res 11(1):3-5

Cleveland DA, Soleri D, Cuevas FA, Crossa J, Gepts P (2005) Detecting (trans)gene flow to landraces in centers of crop origin: lessons from the case of maize in Mexico. Environ Biosaf Res 4(4):197-208. https://doi.org/10.1051/ebr:2006006. (discussion 209-215)

Dalton R (2009) Mexico's transgenic maize under fire. Nature 462(7272):404. https://doi.org/10.1038/ $462404 \mathrm{a}$

Delborne JA (2008) Transgenes and transgressions: scientific dissent as heterogeneous practice. Soc Stud Sci 38(4):509-541

Dyer GA, Serratos-Hernández JA, Perales HR, Gepts P, Piñeyro-Nelson A, Chávez A et al (2009) Dispersal of transgenes through maize seed systems in Mexico. PLoS ONE 4(5):e5734. https://doi.org/10.1371/ journal.pone.0005734

ENGL (2011a) Verification of analytical methods for GMO testing when implementing interlaboratory validated methods-EUR $24790 \mathrm{EN}$-2011, European Union

ENGL (2011b) Overview on the detection, interpretation and reporting on the presence of unauthorised genetically modified materials-EUR 25008 EN-2011, European Union

Fraiture M, Herman P, Taverniers I, De Loose M, Deforce D, Roosens NH (2015) Current and new approaches in GMO detection: challenges and solutions. BioMed Res Int. https://doi.org/10.1155/2015/ 392872

Garcia DA (2017) Monsanto sees prolonged delay on GMO corn permits in Mexico. Thomson Reuters \#Environment http://www.reuters.com/article/us-mexico-monsanto-idUSKBN15E1DJ. Accessed 23 July 2017

Gilbert N (2013) Case studies: a hard look at GM crops. Nature 497(7447):24-26. https://doi.org/10.1038/ 497024a

Graef F, Schmidt G, Schröder W, Stachow U (2005) Determining ecoregions for environmental and GMO monitoring networks. Environ Monit Assess 108(1-3):189-203

Guadagnuolo R, Clegg J, Ellstrand NC (2006) Relative fitness of transgenic vs. non-transgenic maize $\mathrm{x}$ teosinte hybrids: a field evaluation. Ecol Appl 16(5):1967-1974

Heinemann JA, Agapito-Tenfen SZ, Carman JA (2013) A comparative evaluation of the regulation of GM crops or products containing dsRNA and suggested improvements to risk assessments. Environ Int 55:43-55. https://doi.org/10.1016/j.envint.2013.02.010

Hernandez M, Pla M, Esteve T, Prat S, Puigdomenech P, Ferrando A (2003) A specific real-time quantitative PCR detection system for event MON810 in maize YieldGard based on the 30-transgene integration sequence. Transgenic Res 12:179-189

Holden MJ, Blasic JR Jr, Bussjaeger L, Kao C, Shokere LA, Kendall DC, Freese L, Jenkins GR (2003) Evaluation of extraction methodologies for corn kernel (Zea mays) DNA for detection of trace amounts of biotechnology-derived DNA. J Agric Food Chem 51(9):2468-2474

Holst-Jensen A, De Loose M, Van den Eede G (2006) Coherence between legal requirements and approaches for detection of genetically modified organisms (GMOs) and their derived products. J Agric Food Chem 54(8):2799-2809. https://doi.org/10.1021/jf052849a

Holst-Jensen A, Bertheau Y, de Loose M, Grohmann L, Hamels S, Hougs L et al (2012) Detecting unauthorized genetically modified organisms (GMOs) and derived materials. Biotechnol Adv 30(6):1318-1335. https://doi.org/10.1016/j.biotechadv.2012.01.024

Horgan GW, Glasbey CA (1995) Uses of digital image analysis in electrophoresis. Electrophoresis 16:298-305

Kaplinsky N, Braun D, Lisch D, Hay A, Hake S, Freeling M (2002) Biodiversity (Communications arising): maize transgene results in Mexico are artefacts. Nature 416(6881):601-602 (discussion 600, 602)

Lezaun J (2006) Creating a new object of government: making genetically modified organisms traceable. Soc Stud Sci 36(4):499-531 
Macarthur R, Murray AW, Allnutt TR, Deppe C, Hird HJ, Kerins GM et al (2007) Model for tuning GMO detection in seed and grain. Nat Biotechnol 25(2):169-170. https://doi.org/10.1038/nbt0207-169

McAfee K (2008) Beyond techno-science: transgenic maize in the fight over Mexico's future. Geoforum 39:148-160. https://doi.org/10.1016/j.geoforum.2007.06.002

Mercer KL, Wainwright JD (2008) Gene flow from transgenic maize to landraces in Mexico: an analysis. Agr Ecosyst Environ 123:109-115. https://doi.org/10.1016/j.agee.2007.05.007

Mercer KL, Perales H, Wainwright J (2012) Climate change and the transgenic adaptation strategy: smallholder livelihoods, climate justice, and maize landraces in Mexico. Global Environ Change 22(2):495-504

Metz M, Fütterer J (2002) Biodiversity (Communications arising): suspect evidence of transgenic contamination. Nature 416(6881):600-601. https://doi.org/10.1038/nature738

Nielsen KM (2013) Biosafety data as confidential business information. PLoS Biol 11(3):e1001499. https:// doi.org/10.1371/journal.pbio.1001499

Ortiz-García S, Ezcurra E, Schoel B, Acevedo F, Soberón J, Snow AA (2005a) Absence of detectable transgenes in local landraces of maize in Oaxaca, Mexico (2003-2004). Proc Natl Acad Sci USA 102(35):12338-12343. https://doi.org/10.1073/pnas.0503356102

Ortiz-García S, Ezcurra E, Schoel B, Acevedo F, Soberón J, Snow AA (2005b) Reply to Cleveland et al.'s "detecting (trans) gene flow to landraces in centers of crop origin: lessons from the case of maize in Mexico”. Environ Biosafety Res 4:209-215. https://doi.org/10.1051/ebr:2006007

Pavlopoulos A (2011) Identification of DNA sequences that flank a known region by inverse PCR. Methods Mol Biol 772:267-275. https://doi.org/10.1007/978-1-61779-228-1_16

Pearson WR (2014) BLAST and FASTA similarity searching for multiple sequence alignment. Methods Mol Biol 1079:75-101. https://doi.org/10.1007/978-1-62703-646-7_5

Piñeyro-Nelson A, Van Heerwaarden J, Perales HR, Serratos-Hernández JA, Rangel A, Hufford MB et al (2009a) Transgenes in Mexican maize: molecular evidence and methodological considerations for GMO detection in landrace populations. Mol Ecol 18(4):750-761. https://doi.org/10.1111/j.1365294X.2008.03993.x

Piñeyro-Nelson A, Van Heerwaarden J, Perales HR, Serratos-Hernández JA, Rangel A, Hufford MB et al (2009b) Resolution of the Mexican transgene detection controversy: error sources and scientific practice in commercial and ecological contexts. Mol Ecol 18:4145-4150. https://doi.org/10.1111/j. 1365-294X.2009.04369.x

Prakoso B, Nitisinprasert S, Stevens WF (2003) Genetically modified soybeans: false-positive detection in fermented natural soybean (tempe). Biotechnol Lett 25(18):1485-1490

Quist D (2007) Vertical (trans)gene flow: implications for crop diversity and wild relatives. In: Traavik T, Lim LC (eds) Biosafety first. Tapir Academic Press, Trondheim, p 2007

Quist D, Catacora-Vargas G (2011) Transgenes in Mexican maize, ten years on: still not addressing the right questions. GenØk Biosafety Report 2011/04

Quist D, Chapela IH (2001) Transgenic DNA introgressed into traditional maize landraces in Oaxaca. Mexico. Nature 414(6863):541-543

Quist D, Chapela IH (2002) Biodiversity (Communications arising): reply to: maize transgene results in Mexico are artefacts. Nature 416(6881):601-602. https://doi.org/10.1038/nature740

Sarewitz D (2004) How science makes environmental controversies worse. Environ Sci Policy 7(5):385-403. https://doi.org/10.1016/j.envsci.2004.06.001

Schoel B, Fagan J (2009) Insufficient evidence for the discovery of transgenes in Mexican landraces. Mol Ecol 18(20):4143-4144. https://doi.org/10.1111/j.1365-294X.2009.04368.x (discussion 4145-4150)

Schrader C, Schielke A, Ellerbroek L, Johne R (2012) PCR inhibitors-occurrence, properties and removal. J Appl Microbiol 113(5):1014-1026. https://doi.org/10.1111/j.1365-2672.2012.05384.x

Serratos-Hernández JA, Islas-Gutiérrez F, Buendía-Rodríguez E, Berthaud J (2004) Gene flow scenarios with transgenic maize in Mexico. Environ Biosafety Res 3(3):149-157. https://doi.org/10.1051/ebr: 2004013

Serratos-Hernández JA, Gómez-Olivares JL, Salinas-Arreortua N, Buendía-Rodríguez E, Islas-Gutiérrez F, Ita A (2007) Transgenic proteins in maize in the soil conservation area of Federal District. Mexico. Front Ecol Environ 5(5):247-252. https://doi.org/10.1890/1540-9295(2007)5[247:TPIMIT]2.0.CO;2

Snow A (2009) Unwanted transgenes re-discovered in Oaxacan maize. Mol Ecol 18(4):569-571. https://doi. org/10.1111/j.1365-294X.2008.04063.X

Stefano B, Patrizia B, Matteo C, Massimo G (2016) Inverse PCR and quantitative PCR as alternative methods to Southern blotting analysis to assess transgene copy number and characterize the integration site in transgenic woody plants. Biochem Genet 54(3):291-305. https://doi.org/10.1007/s10528-0169719-z 
Stewart CN Jr, Halfhill MD, Warwick SI (2003) Transgene introgression from genetically modified crops to their wild relatives. Nat Rev Genet 4(10):806-817

Trifa Y, Zhang D (2004) DNA content in embryo and endosperm of maize kernel (Zea mays L.): impact on GMO quantification. J Agric Food Chem 52(5):1044-1048

Triglia T, Peterson MG, Kemp DJ (1988) A procedure for in vitro amplification of DNA segments that lie outside the boundaries of known sequences. Nucleic Acids Res 16:8186

van Heerwaarden J, Ortega Del Vecchyo D, Alvarez-Buylla ER, Bellon MR (2012) New genes in traditional seed systems: diffusion, detectability and persistence of transgenes in a maize metapopulation. PLoS ONE 10:e46123. https://doi.org/10.1371/journal.pone.0046123

Vargas-Parada L (2014) GM maize splits Mexico. Nature 511(7507):16-17. https://doi.org/10.1038/ $511016 \mathrm{a}$

Wainwright J, Mercer KL (2011) Transnational transgenes: the political ecology of maize in Mexico. In: Peet R, Robbins P, Watts M (eds) Global political ecologies. Routledge, New York, pp 412-429

Walz U, Hoechstetter S, Drăguţ L, Blaschke T (2016) Integrating time and the third spatial dimension in landscape structure analysis. Landscape Res. https://doi.org/10.1080/01426397.2015.1078455

Wickson F (2014) Environmental protection goals, policy and publics in the European regulation of GMOs. Ecol Econ 108:269-273

Wickson F, Bøhn T, Wynne B, Hilbeck A, Funtowicz S (2013) Science-based risk assessment requires careful evaluation of all studies. Nat Biotechnol 31:1077-1078

Wu Y, Wang Y, Li J, Li W, Zhang L, Li Y et al (2014) Development of a general method for detection and quantification of the P35S promoter based on assessment of existing methods. Sci Rep 4:7358. https:// doi.org/10.1038/srep07358

Yuan JS, Burris J, Stewart NR, Mentewab A, Stewart CN Jr (2007) Statistical tools for transgene copy number estimation based on real-time PCR. BMC Bioinform 8(Suppl 7):S6. https://doi.org/10.1186/ 1471-2105-8-S7-S6

Zel J, Milavec M, Morisset D, Plan D, Van den Eede G, Gruden K (2012) How to reliably test for GMOs, 1st edn. Springer, New York. https://doi.org/10.1007/978-1-4614-1390-5_1 